\title{
Modified One-Piece Extended Transbasal Approach for Endoscopic-Assisted Microsurgical Resection of Tuberculum Sellae Meningioma: Operative Video and Technical Nuances
}

James K. Liu, MD ${ }^{1} \quad$ Kentaro Watanabe, MD ${ }^{1}$

${ }^{1}$ Department of Neurological Surgery, Center for Skull Base and Pituitary Surgery, Neurological Institute of New Jersey, Rutgers University, New Jersey Medical School, Newark, New Jersey

J Neurol Surg B 2018;79(suppl S2):S213-S214.

\begin{abstract}
Address for correspondence James K. Liu, MD, Department of Neurological Surgery, Rutgers University, New Jersey Medical School, 90 Bergen Street, Suite 8100, Newark, New Jersey 07103 (e-mail: james.liu.md@rutgers.edu).
\end{abstract}

\begin{abstract}
Keywords

- tuberculum sellae meningioma

- transbasal approach

- microsurgical technique

- endoscopic-assisted microsurgery

- operative video
\end{abstract}

The optimal approach for surgical resection of tuberculum sellae meningiomas remains controversial. Approach selection is largely based on a variety of factors, such as tumor size, extent and location relative to the optic canal and internal carotid artery, the presence of vascular encasement, and surgeon's preference. In this operative video manuscript, the authors demonstrate the importance of an open transcranial approach when the tumor extends lateral to the optic nerve over the internal carotid artery into the opticocarotid triangle, which is a difficult region to safely access with a purely endoscopic endonasal approach. We present a case of an endoscopic-assisted microsurgical resection of a tuberculum sellae meningioma using a modified one-piece extended transbasal approach in a patient with unilateral visual loss. The approach allows both interhemispheric and subfrontal routes to the suprasellar region. Early optic nerve decompression and division of the falciform ligament is critical to optimize visual outcomes. This video atlas demonstrates the operative technique and surgical nuances of the skull base approach, optic nerve decompression, tumor-arachnoid dissection, and safe handling of the neurovascular structures. A gross total resection was achieved and the patient had restoration of normal vision with normal pituitary function. In summary, the modified one-piece extended transbasal approach with endoscopic assistance is an important strategy in the armamentarium for surgical management of tuberculum sellae meningiomas.

The link to the video can be found at: https://www.youtube.com/watch?v=jKNtRzMSFVE.

Conflict of Interest

None declared.

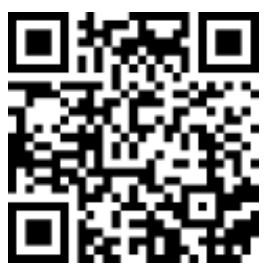

www.thieme.com/skullbasevideos

www.thieme.com/jnlsbvideos

published online November 1, 2017
DOI https://doi.org/

10.1055/s-0037-1606553. ISSN 2193-6331.
(C) 2018 Georg Thieme Verlag KG Stuttgart · New York
License terms

() (1) $\ominus \circledast$ 

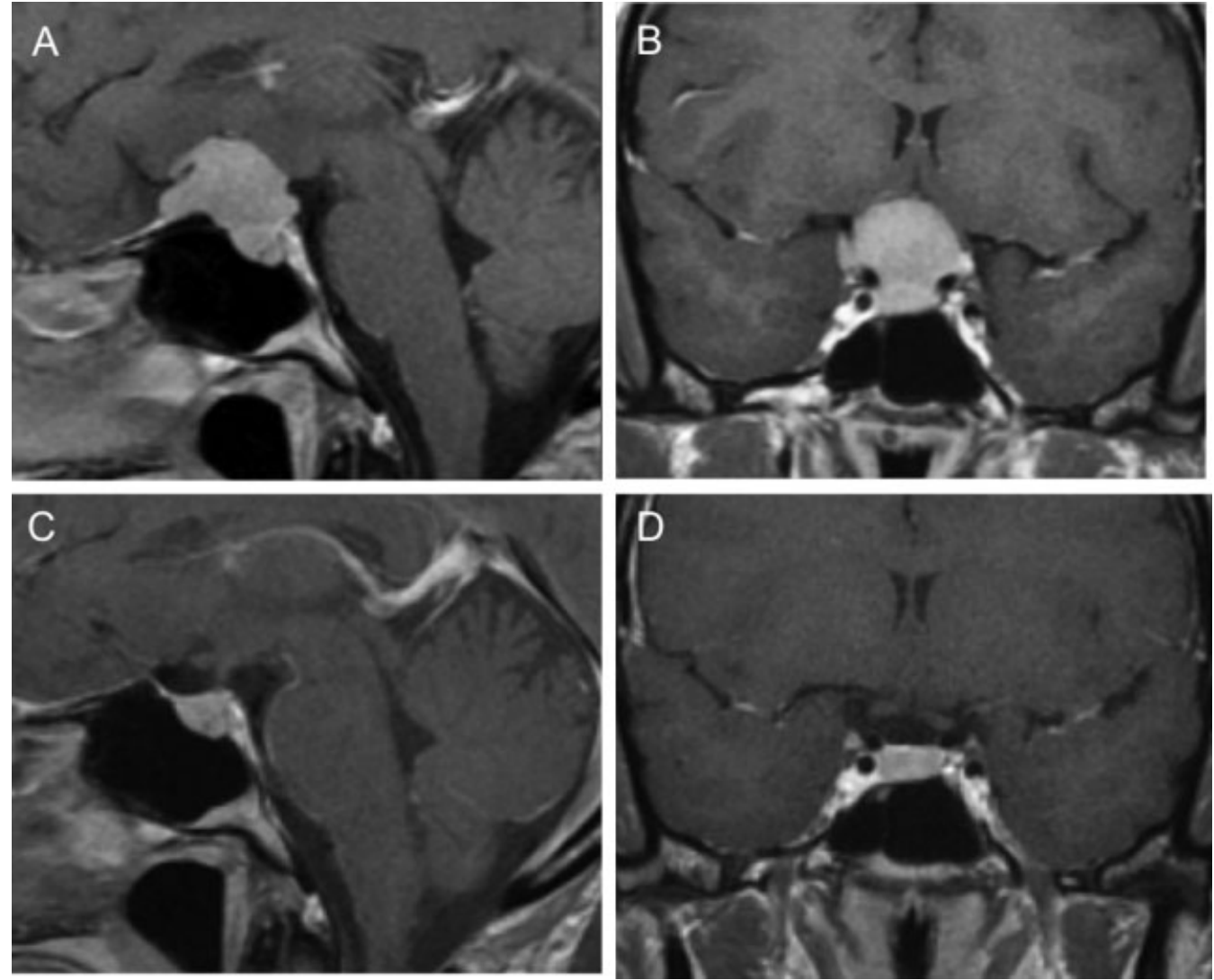

Fig. 1 Preoperative (A and $B$ ) and postoperative ( $C$ and $D)$ post-gadolinium T1-weighted MRI of a tuberculum sellae meningioma removed via a modified one-piece extended transbasal approach.

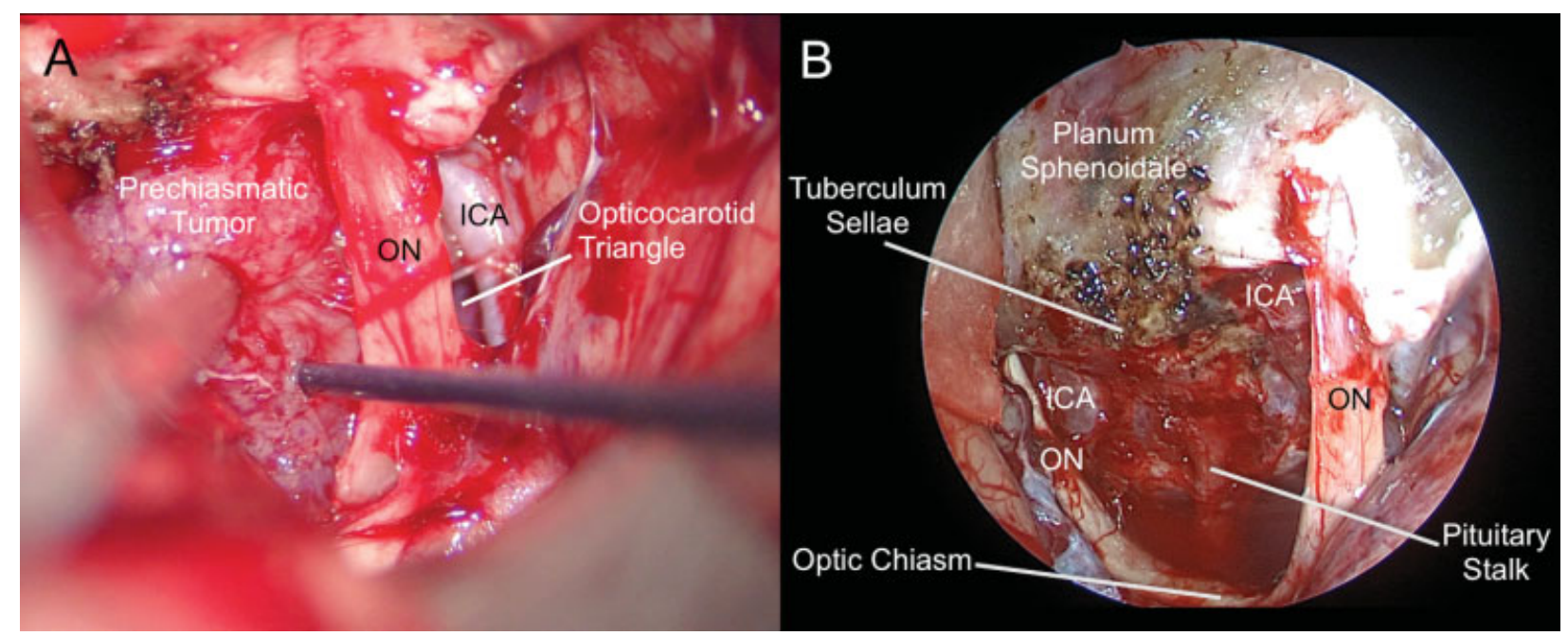

Fig. 2 (A) Intraoperative microsurgical view of tumor removal via the right subfrontal route. (B) Endoscopic view of suprasellar region after tumor removal. 